\title{
L. The radiation from ordinary materials
}

\section{Norman R. Campbell B.A.}

To cite this article: Norman R. Campbell B.A. (1905) L. The radiation from ordinary materials , Philosophical Magazine, 9:52, 531-544, DOI: 10.1080/14786440509463304

To link to this article: http://dx.doi.org/10.1080/14786440509463304

册 Published online: 08 Jun 2010.

Submit your article to this journal $\pi$

Џ Article views: 4

Q View related articles $\sqsubset$

47 Citing articles: 7 View citing articles 진 
a glance how entirely different these curves are from those for the other metals investigated. I have no explanation for this difference, but it is well known that iron and steel are anomalous in many other properties. The steel wires after having been stretched are magnetized, and this suggests that a molecular change may take place in the steel, perhaps at a definite point in the stretching, causing the steel at that point to become harder.

Up to the present no other substances have been investigated, but it is my intention to investigate the behaviour of quartz fibres in the same way. They have been shown to be very perfectly elastic for small distortions, but it is quite possible that a slow creep does take place and could be detected if much larger distortions were used.

My best thanks are due to Prof. Poynting for his many valuable and kindly suggestions throughout the research.

Birmingham University, Oct. 1904.

L. The Radiation from Ordinary Materiuls. By Nonman R. Campbeld, B.A., Fellow of Trinity College, Cumbridge*.

[Plate VII.]

$\S 1$. THE experiments of Patterson, MeLennan, Strutt, Righi, and others, have proved beyond doubt that part of the "spontaneous" ionization in a closed vessel containing gas is due to the influence of the walls. It is of the utmost importance to determine the nature of this influence - to ascertain whether it consists of Becquerel rays, and, if so, to discover the nature of those rays.

In this paper $\dagger$ two methods are described which have been used for the solution of the problem, the later being suggested by the earlier work.

$\S 2$. All the experiments consisted in the measurement of the spontaneous saturation current-or "leak," as it will be called hereafter-through vessels of various forms and materials. A preliminary description of the apparatus used for the measurement is desirable.

A Wilson gold-leaf electroscope $\ddagger$ was employed and found most satisfactory. The potential to which the insulated system had attained in a given time was ascertained by means

* Communicated by Prof. J. J. Thomson.

+ This paper contains an account of the experiments, the results of which were briefly indicated in a letter to the Editor of 'Nature' (vol. lxix. p. 5l1).

$\neq$ C. T. R. Wilson, Proc. Camb. Phil. Soc. vol. xii. p. 135 (1903). 
of the arrangement shown in fig. 1. The point on the scale of the observing microscope occupied by the leaf was noted, the electrode earthed by inserting the wire $\mathrm{C}$ in the mercury

Fig. 1.

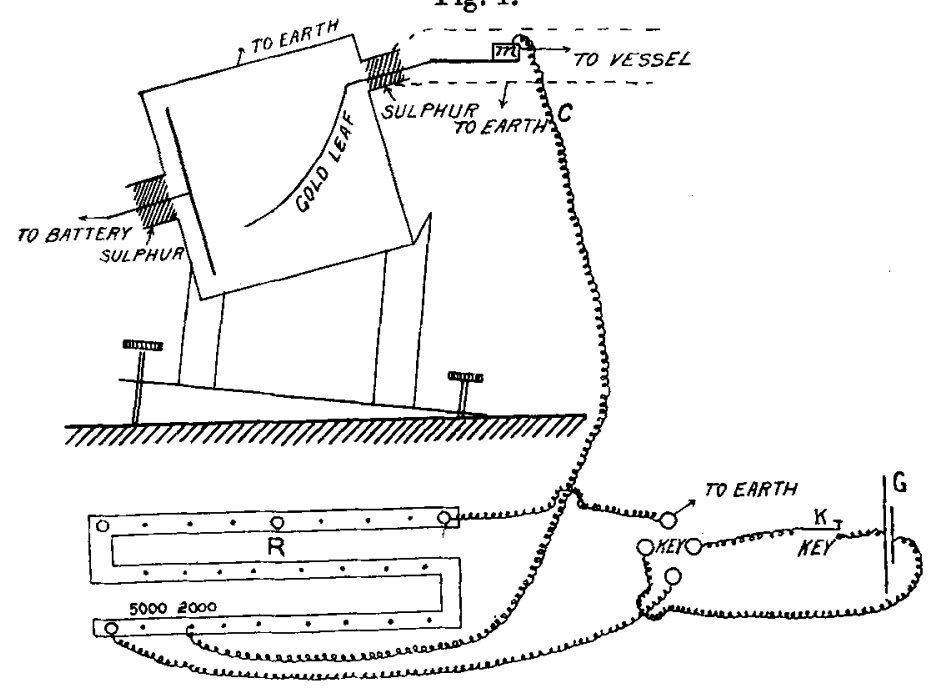

cup $m$, and resistances taken out of the box $\mathrm{R}$ until, on depressing the key $K$, the leaf returned to the position noted : from the value of the resistances and of the E.M.F. of the cell $G$ the required potential can be easily calculated.

The time for which the leak was measured was chosen so that the potential acquired was about one volt, giving 55 to 60 scale-divisions; the potential could be read with an accuracy of one per cent.

The field necessary to send the saturation current through the gas was derived from an excellent battery of small cells. Care was taken that the current was saturated and that all insulation (sulphur was used throughout) was acting efficiently. The direction of the field was occasionally reversed; in all cases in which the contrary is not explicitly stated, the magnitude of the leak was independent of its sign.

The capacity of the insulated electrode system, the product of which with the potential acquired in unit time gives the current through the gas, was measured by means of the device described by McClelland *. The current is given throughout the paper on an arbitrary scale, in which the unit of capacity

* McClelland, Roy. Dublin Soc. Proc. 10. 18, p. 167 (Feb. 26, 1904). 
is the capacity of the "Uranium Pot" used (a lead cylinder $17 \mathrm{~cm}$. high and $9 \mathrm{~cm}$. in diameter, with a central wire electrode), the unit of potential the volt, and the unit of time the minute.

Since the reading of one electroscope did not wholly occupy the attention of the observer, two exactly similar but entirely separate sets of apparatus were used: thus two experiments were proceeding at the same time. On several occasions the same experiment was tried successively with the two electroscopes, and excellent agreement between the results obtained.

\$3. A few preliminary experiments were made with vessels of the same dimensions as the "Uranium Pot," but of the most diverse materials-metals, woods, paper, porous pots saturated with electrolytes, \&c. The leak in all cases was of the same order of magnitude, the extremes differing in the ratio of 7 to 1 .

$\S 4$. The first method by which information was sought as to the nature of the ionizing influence was the measurement of the relation between the ionization and the volume in vessels of special form.

Rectangular vessels were constructed of wood, of which one side could be moved parallel to itself through a considerable range (fig. 2). The walls were covered with the material

Fig. 2.

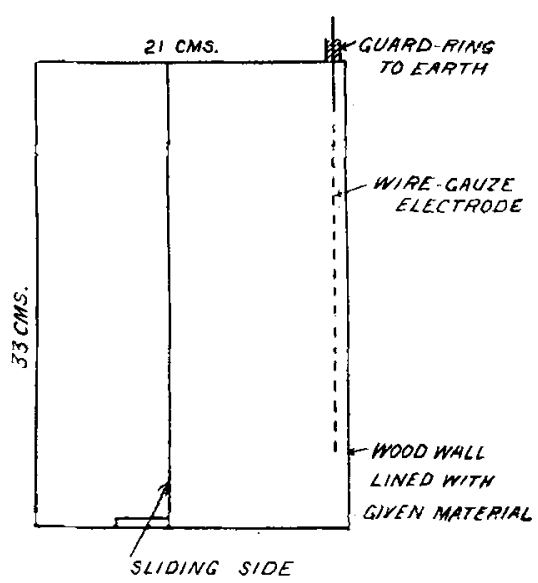

under investigation, carefully cleaned with sandpaper and charged to a high potential ; the current through the gas to an electrode of wire netting, suspended by a stiff wire passing through a sulphur plug and guard-ring in the top of the vessel, 
was measured by the electroscope: The surface of the wire forming the electrode was so small that its influence was negligible comprared with that of the walls of the vessels.

The front wall could be removed in order to adjust the sliding side; it is supposed to be removed in the figure to show the interior arrangement. The dimension of the sliding side was about $33 \times 23 \mathrm{cms}$., differing slightly in different boxes; the range was some $22 \mathrm{cms}$.

The following materials were used as coverings for the walls :-

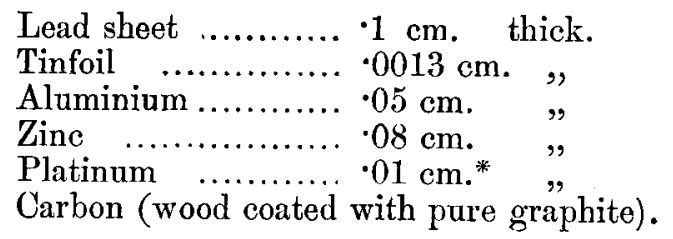

The results of the experiments are expressed in the curves of fig. 1, Plate VII. $\dagger$ Each point marked on a curve represents the mean of at least fifteen observations-usually a far greater number. The plotting of each curve occupied from seven to ten days.

$\S 5$. Before proceeding to the discussion of the curves some attention should be given to a difficulty which seriously obstructed the progress of the work. This difficulty is the variation which was found to occur in the value of the leak through a given volume.

The variations were of two kinds :-

(1) A slight continuous and continual change over a range of 15 or 20 per cent. No serious trouble arose from this cause ; by taking the mean of some 25 readings a value could always be obtained which could be reproduced to within 4 or 5 per cent. at any subsequent time by replacing the sliding side in the same position-so long as changes of this kind only had occurred in the interval.

(2) Sudden discontinuous changes or "jumps," when the value of the leak might be altered by as much as 50 per cent. These were far more troublesome. They occurred on an average once in 2 or 3 days, and affected in the same sense the values all over the range. The leak could not be brought back to its original value by blowing in fresh air or cleaning the surface of the walls; the occurrence of the variations

* For the loan of the considerable quantity of platinum required, I am indebted to the generosity of Messrs. Johnson, Matthey \& Co.

t The curve for platinum is so nearly coincident with that for aluminium that it has not been drawn. 
could not be prevented nor their abolition secured by any of the numerous measures that were tried. They were indubitably changes in the ionization due to the walls, for they affected the leak at small volumes in a greater ratio than the leak at large volumes, but their cause has remained a mystery.

It might be thought that jumps of this kind would render impossible the plotting of such curves as have been drawn; but fortunately they were well marked-there was never any doubt when one had occurred. By patiently continuing observations, a period between two jumps could always be found sufficiently long to enable a complete series of observations to be made throughout the whole range of the sliding side. But if the series had been made in a different interval, the constants of the curve-but not, so far as can be ascertained, its form-would have been markedly different.

Dr. Jaffé has recently published in this Magazine * a paper in which he has given some account of similar changes which he observed. Our experiments were in progress at the same time and in the same laboratory; and it is worthy of note that while changes of type (1) occurred in general with both of us at the same time in the same sense, no correlation could be established between changes of type (2).

The vessels which I used were not perfectly air-tight, but it seems improbable that this fact is the cause of the changes, in view of the impossibility of restoring the leak to its former value by blowing in fresh air from outside the room.

$\S 6$. We will now consider the meaning of the curves of fig. 1, Plate VII. The difference between the curved portion near the origin and the straight line into which it develops suggests at once that two different agents are at work; and we can easily see that the form of the curve can be explained on the assumption that the ionization is caused by an easily absorbable radiation proceeding from the walls acting in conjunction with a much more penetrating radiation. For this penetrating radiation, not being perceptibly decreased in intensity by passing through the air of the vessel, will cause ionization proportional to the volume; the part of the curve due to this cause will be a straight line inclined to the axis. On the other hand, the ionization caused by easily absorbable radiation coming from the walls will increase with the distance apart of the sliding sides, only so long as a layer of air of a thickness equal to that distance is instfficient to absorb all the radiation. When all the radiation is absorbed in passing from one side of the box to the other, an increase in the

$$
\text { * Jaffé, Phil, Mag. Oct. } 1904 .
$$


distance between the sides will cause no increase in the resulting ionization. The part of the curve due to this cause will increase rapidly to a constant value. Combining the two, we should expect a rapid rise of the curve near the origin followed by a straight line cutting the axis of ionization on the positive side. This is precisely the form of the curres in the figure.

Reasoning from the assumption of the existence of these two radiations, we can obtain some information as to their intensities.

Let each sq. $\mathrm{cm}$. of the walls give out $(a)$ an amount of absorbable radiation which, when totally absorbed by the air, causes ionization $s$, and $(b)$ an amount of penetrating radiation which causes ionization $v_{1}$ per c.c.; $(c)$ let the external penetrating radiation discovered by Cooke* cause ionization $v_{2}$ per c.c.

Then, if $x$ is the distance apart of the movable sides, $c$ and $d$ the lengths of their edges, the surface of the box exposed to the air inside is

$$
2 c d+2(c+d) \cdot c
$$

and the volume of the air contained is $c d x$.

When $x$ is so great that all the radiation ( $\alpha$ ) is absorbed, the jonization in the vessel will be

$$
\begin{array}{cc}
\{2 c d+2(c+d) x\} s & \text { due to }(a) \\
\{2 c d+2(c+d) x\} v_{1} c d x & \text { due to }(b) \\
c d x v_{2} & \text { dus to }(c) .
\end{array}
$$

If $y$ is the total ionization the equation of the curve remote from the origin is

$$
y=2 c d s+\left\{2(c+d) s+2 c^{2} d^{2} v_{1}+c d v_{2}\right\} x+2 c d(c+d) v_{1} x^{2} .
$$

Now we see that the part of our curves remote from the origin is indistinguishable from a straight line; hence we may put $v_{1}=0$ and obtain

$$
y=2 c d s+\left\{2(c+d) s+c d v_{2}\right\} x .
$$

Produce the straight portion of the curve to cut the axis of $y$; let the intercept on this axis be $p$. Then

$$
p=2 c d s \text { or } s=\frac{2 c d}{p} \text {. }
$$

The tangent of the angle which the straight line makes with the axis of $x$ is $\tan \theta=2(c+d) s+c d v_{2}$. From the

* H. L. Cooke, Phil, Mag. Oct. 1903. 
experimental curves we know $c, d, p, \theta$, hence $s$ and $v_{2}$ can be calculated. The values found in this way are given in Table I., columns 2 and 3.

TABLE I.

\begin{tabular}{|c|c|c|c|c|c|c|c|}
\hline 1 & 2 & 3 & 4 & 5 & 6 & $r$ & 8 \\
\hline \multirow[t]{2}{*}{ Material. } & \multicolumn{2}{|c|}{ Without Screen. } & \multicolumn{2}{|c|}{ With Screen. } & \multicolumn{3}{|c|}{ Dimensions of Box. } \\
\hline & $s \times 10^{4}$ & $v_{3} \times 10^{5}$ & $s^{\prime} \times 10^{4}$ & $v_{2}^{\prime} \times 10^{5}$ & $c d$. & $c+d$ & Range \\
\hline Lead & $3 \cdot 86$ & $3 \cdot 22$ & $3 \cdot 84$ & $1 \cdot 31$ & 777 & $56 \cdot 4$ & 21 \\
\hline Tinfoil & $3 \cdot 3$ & 0.92 & $2 \cdot 15$ & $0-43$ & 792 & $57 \cdot 0$ & 20 \\
\hline Aluminium. & $1 \cdot 0$ & $3 \cdot 19$ & $1 \cdot 0$ & $0 \cdot 88$ & 710 & $53 \cdot 8$ & 22 \\
\hline Zine $\ldots . . . .$. & $0 \cdot 8$ & $2 \cdot 76$ & $0 \cdot 47$ & $1 \cdot 33$ & 710 & $53 \cdot 8$ & 20 \\
\hline Platinum & 0.92 & $3 \cdot 36$ & $0 \cdot 0$ & $2 \cdot 2$ & 780 & $56 \cdot 6$ & 21 \\
\hline Graphite & $2 \cdot 04$ & 1.54 & $1 \cdot 69$ & $0 \cdot 83$ & 710 & $53 \cdot 8$ & 22 \\
\hline
\end{tabular}

$\S 7$. The curved portion of the trace requires further consideration. In this region the distance between the sides is so small, that the absorbable radiation is not wholly absorbed in traversing: the layer of air, and consequently does not exert its full ionizing effect. For this part of the curve the ionization due to each sq. $\mathrm{em}$. of the walls will be an exponential function of $x$ and $\lambda$, the absorption coefficient, say $f(x, \lambda)$. Of course $s=f(\infty, \lambda)$.

If we could determine the form of the function we could determine $\lambda$ from the curve, but in order to do this we must know the relation between the intensity of the radiation emitted in each direction and the angle that direction makes with the normal to the radiating surface. Thus, if the rays were all projected normally,

$$
f(x, \lambda)=\frac{\mathbf{I}_{0}\left(\mathrm{I}-e^{-\lambda x}\right)}{\lambda}
$$

where $I$ is the ionization caused actually at the surface. If the rays are emitted equally in all directions,

$$
f(x, \lambda)=2 \pi \mathrm{I}_{0}\left\{\frac{1-e^{-\lambda x}}{\lambda}+x \int_{x}^{\infty} e^{-\lambda r} d r\right\} .
$$

Ideally it would be possible to determine from the earlier part of the curve the function applicable to the case and the value of $\lambda$ for any metal. But actually it is not possible to draw this portion with sufficient accuracy for the purpose ;

$$
\text { Phil. Mag. S. 6. Vol. 9. No. 52. April 1905. } 2 \mathrm{~N}
$$


the volumes are small and the probable error great. The matter is complicated by the influence of the corners of the box ; at the edges of any wall part of the rays, unless they proceed normally from the surface, will be cut off by the adjacent wall and fail to exert their full effect. When account is taken of this, $f(a, \lambda)$ becomes too complicated for further progress to be made in this direction. It might appear at first sight possible to assume that the rays were emitted equally in all directions; for the properties along any line in an infinite slab of material-and for this purpose the thicknesses used may be considered infinite-should be independent of the direction of that line. But the values of $\lambda$ obtained on this assumption are so utterly discordant with those found in the experiments described below that the assumption must be rejected. Probably the inequalities of the surface have an influence which cannot be neglected. Much better agreement is also found between the calculated and plotted curves on the assumption that all rays are projected normally.

For these reasons the attempt to deduce values of $\lambda$ from the curves has been abandoned. But it is readily seen that the values of $\lambda$ cannot be the same or nearly the same, for different materials. The distance from the origin at which the curve becomes appreciably straight will clearly be some measure of the penetration of the rays : it is evident then that $\lambda$ for carbon and tin is less than for lead and aluminium.

Experiments are in preparation in which the complicated effects of the corners will be eliminated, and, it is hoped, greater accuracy obtained. It may then be possible to determine $I_{0}$ and $\lambda$, and to ascertain whether $v_{1}$ is or is not accurately zero.

$\S 8$. Observations of the same nature were subsequently made in which the boxes were surrounded by some 150 kilos. of lead forming a layer about $3 \mathrm{cms}$. thick; this screen should reduce by $2 / 3$ the intensity of Cooke's penetrating radiation.

The resulting curves are given in fig. 2, Pl. VII., and the values of $s$ and $v_{2}$ deduced from them in Table I., columns 4 and 5. It is to be noted that the value of $s$ is reduced in the cases of tin, carbon, zinc, and platinum, but remains unaltered in lead and aluminium. 'That is to say, in the former materials, the intensity of the radiation proceeding from the walls themselves is reduced by a screen outside the walls. We have thus strong confirmation of the conclusion reached by Wood *, that part of the spontaneous radiation from ordinary

* A. Wood, Proc. Camb. Phil. Soc. vol. xii. p. 477 (1904). 
materials is secondary radiation excited by external penetrating rays. In the case of platinum all the absorbable radiation appears to be secondary ; the conclusion is remarkable, but I have no reason to think that the experiments with platinum are less accurate than any of the others. It will be noted that the value of $v_{2}$ is not the same for all metals either in column 3 or 5 , as might have been expected if the radiation corresponding to $v_{2}$ was external to the apparatus. But the variations mentioned in $\$ 5$ must be borne in mind. In addition, it shonld be pointed out that the value of $v_{2}$, being calculated as the difference of two comparatively large quantities, is liable to considerable error, and that the introduction of a correction for the effect of the corners of the box would cause a notable alteration.

$\S 9$. It was now considered that sufficient evidence had been obtained of the existence of easily absorbable rays from ordinary materials; experiments were therefore devised by

Fig. 3.

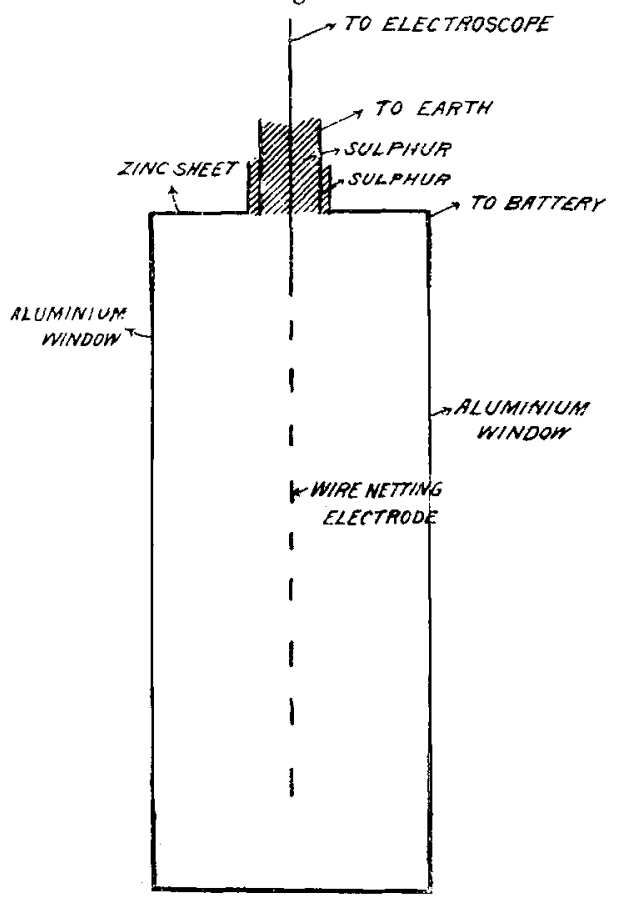

which it was hoped to establish more directly the existence of the rays and to arrive at some knowledge of the value of $\lambda$. A rectangular vessel of zine sheet (fig. 3) was constructed, $2 \mathrm{~N} \hat{z}$ 
$15 \times 15 \times 6 \mathrm{cms}$., in one side of which was a window $12 \times 12$ cms. covered with a sheet of thin aluminium-foil ; the thickness of the foil used in most of the experiments was $.00033 \mathrm{~cm}$.; similar results were obtained with a thickness of $00053 \mathrm{~cm}$., and also with a sheet of very thin paper rendered conducting with graphite.

The observations consisted in ascertaining the leak through the vessel when no solid body was within a distance of one metre from the window, and then noting the effect of bringing up to the window a plate of the material the radiation from which was to be investigated. At first the vessel was charged to a high negative potential, but troubles occurred which were traced to the deposition on the surface of the "excited activity" which is known to collect on all negatively charged bodies exposed to the atmosphere. The amount of the excited activity, the rays from which could penetrate the window, varied with the freedom of access of the outside air to the vessel, and hence the leak was constantly changing. In the later experiments the vessel was always charged positively.

$\$ 10$. If our conclusion is correct that the influence of the walls on the ionization consists of rays projected from them absorbable by some $6 \mathrm{cms}$. of air, we ought to be able to detect the influence of the rays through the aluminium foil, which is equivalent in surface density to $69 \mathrm{~cm}$. of air. Accordingly when plates of lead, tin (foil or plate), aluminium, zinc, iron, brass, copper, graphite, wood, or glass were brought up to the window, an unmistakable increase in the leak was detected -in the case of tin the increase was as much as 30 per cent. It is clear that the increase caused by any material will rise with the penetrating power as well as with the intensity of the rays given off from it ; it is, then, in no way inconsistent with Table $I$. that tinfoil gave a larger effect than lead, and carbon an effect nearly as great. With scme materials, such as paper and ebonite, the increase was so small that it cannot be positively asserted to exist.

Strutt* has found large differences between the effects obtained with different specimens of the same material, but though I have tried several samples of each of the materials. mentioned, appreciably the same value was obtained for each. Strutt must have been extraordinarily unfortunate in securing samples contaminated with radionctive impurities, for McLennan, Righi, and Wood have found remarkable constancy in the value given by different samples of the same metal.

* Strutt, 'Nature, vol. Ixvii. p. 369. 
Tinfoil and tin-plate gave notably different values, but tinfoil is, I believe, an alloy; specimens of foil and plate agreed amongst themselves. Only in the case of wood were iarge differences found, but so porous a material, after lying some time in a laboratory where considerable quantities of pure radium salts have been used, might be expected to acquire a spurious radioactivity.

\$11. An attempt was made to measure the coefficient of absorption of the rays. Three methods were employed :-

(1) By moving the plate away from the window so as to interpose a layer of air of known thickness.

(2) By interposing a layer of aluminium-foil.

(3) By cutting a second window in the other side of the zine vessel, covering it with a layer of aluminium-foil of different thickness, and comparing the increase caused by the plate first before one window and then before the other.

In these ways we can show that the coefficients of absorption of the rays from different materials are not the same, and obtain some estimate of their value. But the attempt to ascertain the value accurately is frustrated by the difficulty we have met before: we do not know the relation between the intensity of the rays from the surface and their inclination to the surtace normal. Thus, if we place a layer of thickness $d$ and absorption $\lambda^{\prime}$ on the face of the material, the effect of the rays will be cut down in the ratio $e^{-\lambda^{\prime} d}$ if the rays are projected normally, and in the ratio $\int_{0}^{l} e^{-\frac{\lambda^{\prime} a}{y}} d y$ if they are equally projected in all directions. In Table II.

Table II.

\begin{tabular}{|c|c|c|}
\hline & \multicolumn{2}{|c|}{ Ratio. } \\
\hline & A. & B. \\
\hline 0.25 & $0 \cdot 78$ & 0.52 \\
\hline 0.5 & $0 \cdot 61$ & $0 \cdot 34$ \\
\hline $0 \cdot 7 \tilde{5}$ & $0 \cdot 47$ & $0 \cdot 26$ \\
\hline 1.00 & 0.37 & $0 \cdot 15$ \\
\hline 2.00 & 0.135 & 0:038 \\
\hline
\end{tabular}

the ratios of reduction are given for different values of $\lambda^{\prime} d$. (A) when the rays are projected normally, (B) when they are emitted equally in all directions. 
In what follows we shall calculate all quantities on the assumption that the rays are ejected normally; we shall thus get a qualitative description of the phenomena which will not be quantitatively correct. We will give one set of readings to exemplify each method.

Method 1.-Tin-plate: window $\cdot 00033 \mathrm{~cm}$. of aluminium.

$\begin{array}{cc}\begin{array}{c}\text { Distance of plate } \\ \text { from window }=x .\end{array} & \begin{array}{c}\text { Inerease of } \\ \text { leak }=\mathrm{I} \text {. }\end{array} \\ 0.5 \mathrm{~cm} . & .021 \\ 0.75,, & .018 \\ 1.00,, & .015 \\ 1.50,, & .008\end{array}$

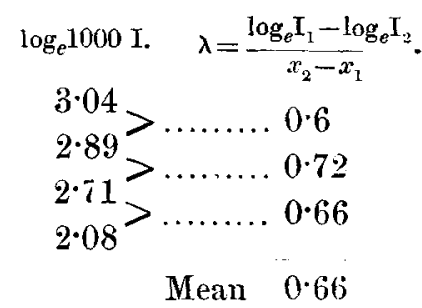

The value of $\lambda$ obtained by moving the plate from 0 to $\check{\mathrm{cm}}$. was always abnormally small and therefore rejected.

Method 2.-Lead.

$\mathbf{I}=$ increase of leak through one $\log _{e} 1000 \mathrm{I}$. leaf over window. .023 $3 \cdot 14$
$I^{\prime}=$ increase with two leaves over $\log _{e} 1000 I^{\prime} . \quad \lambda^{\prime}(\mathrm{Al})^{*} \quad \lambda(\text { air })^{*}$ window. $\cdot 0095$ $1 \cdot 3$

The increase given by zinc and aluminium was too small to be measured by this method.

Method 3.-Lead.

Window covered by Window covered by foil $\cdot 00033 \mathrm{~cm}$. thick. foil $\cdot 00053 \mathrm{~cm}$. thick.

$\lambda^{\prime}(\mathrm{Al}) . \quad \lambda($ air $)$.

$$
\mathrm{I}=\cdot 023 \quad \mathrm{I}^{\prime}=\cdot 014 \quad 2500 \quad 1 \cdot 18
$$

In the first column of Table III., column 1, are given the values of $\lambda$ deduced from the curves by a simple geometrical method on the assumption that all rays are projected normally; in columns $2,3,4$ are given the values found by methods 1,2, and 3 above. In Table IV. the increases which should be caused by the various materials placed outside the window are calculated on the same assumption and compared with those actually found.

\$12. The agreement in Table III. and in Table IV. is only qualitative ; but it must be remembered that the assumption on which the figures are calculated is almost certainly incorrect.

* The absorption coefficients for air and aluminium are compared throughout on the assumption that they are proportional to the densities of those substances. 
'TabLe III.

\begin{tabular}{|c|c|c|c|c|c|}
\hline \multirow[t]{2}{*}{ Material } & \multicolumn{4}{|c|}{ Absorption Coefficient. } & \\
\hline & 1 & 2 & 3 & 4 & Mean. \\
\hline Lead ............. & 0.91 & $1 \cdot 28$ & $1 \cdot 3$ & $1 \cdot 18$ & $1 \cdot 17$ \\
\hline $\operatorname{Tin} \ldots$. & 0.45 & 0.66 & 0.71 & 0.8 & 0.65 \\
\hline Carbon ............ & $0 \cdot 27$ & 0.52 & 0.47 & 0.52 & $0 \cdot 44$ \\
\hline Aluminium ..... & $0 \cdot 61$ & $\ldots$ & $\ldots$ & 1.00 & 0.8 \\
\hline Zinc .............. & $0 \cdot 36$ & $\ldots$ & .. & 07 & $0 \div 5$ \\
\hline Platiuum ........ & 0.56 & $\cdots$ & $\cdots$ & $\ldots$ & 0.56 \\
\hline
\end{tabular}

Table IV.

\begin{tabular}{|c|c|c|} 
Material. & \multicolumn{2}{|c|}{ Increase of Leak. } \\
& Observed. & Calculated. \\
\hline & & \\
\hline Lead ............. & 0.023 & 0.0245 \\
Tinfoil ........... & 0.025 & 0.0305 \\
Aluminium ....... & 0.0075 & 0.0084 \\
Zinc ............. & 0.0055 & 0.0077 \\
Carbon ............ & 0.020 & 0.022 \\
\hline
\end{tabular}

But I think the experiments have proved sufficiently that the coefficient of absorption is not the same for the rays from different materials - that each material emits rays of a quality peculiar to itself.

The importance of this conclusion, if acepted, can hardly be overestimated. If the rays from different materials are of different quality, it is impossible that they should be given out by traces of a radioactive impurity common to all. Again, the presence of a radioactive impurity-a suggestion that has received considerable support-seems hardly able to explain the remarkable constancy of the intensity of the radiations emitted by samples of metals derived from different sources.

$\S 13$. Experiments in which the plates of metal outside the window were backed with slabs of iron $2.5 \mathrm{cms}$. thick confirmed the conclusion previously reached that part of the radiation from zinc, tin, and carbon is secondary, excited by a penetrating radiation from outside. 
$\S 14$. No evidence whatever could be obtained of the existence of rays from ordinary materials more penetrating than those which have hitherto been considered. If the window of the box was covered with a layer of aluminium $\cdot 003 \mathrm{~cm}$. thick, no increase amounting to 2 per cent. of the normal leak was caused by placing before the window any of the ordinary materials used in these experiments. Such a thickness of aluminium would scarcely cause an appreciable diminution in the intensity of rays as penetrating as the $\beta$ rays from radium or uranium. Hence, again we are led to the conclusion that $v_{1}$ of $\S 6$ is zero.

$\S 15$. The conclusions which are considered to be established by the experiment described in this paper may be put briefly as follows:-

(1) That the influence, which the walls of a containing vessel are known to exert upon the spontaneous ionization of the enclosed air, may be attributed to a radiation proceeding from the walls.

(2) That part of this radiation from certain materials, such as tin, zinc, graphite, and platinum, is analogous to the secondary radiation excited by Röntgen and other rays, being caused by the penetrating ionizing rays which Cooke has cut off with thick lead screens.

(3) That the absorption coefficient of air for this radiation is comparable with that of air for the $\alpha$ rays from radium.

(4) That the absorption coefficient is different for different materials, and hence it is unlikely that the radiation is due to radioactive impurities; it is more probably an inherent property of the material *.

(5) That there is no evidence of the existence of rays from ordinary materials of a penetrating power considerably greater than that of the $a$ rays from radioactive elements.

It is obviously a matter of great importance to determine the nature. of the rays from ordinary materials-their charge, if they carry a charge, their velocity, and so on. But the investigation of these properties will tax the ingenuity of the ablest experimenter.

These experiments were carried out in the Cavendish Laboratory, Cambridge. When this is stated it is hardly necessary to add that a large portion of whatever success has attended them is due to the inspiring advice of Prof. Thomson.

Cambridge, Jan. 1905.

* Most of the radioactive elements give off an emanation. It is here suggested that all elements are radioactive to some degree. It might be expected that some would give off an emanation. All efforts to directly detect such an emanation from lead, zinc, and aluminiuin have hitherto failed. 
Phil. Mag. Ser. 6, Vol. 9, Pl. VII.

Fig. 1.

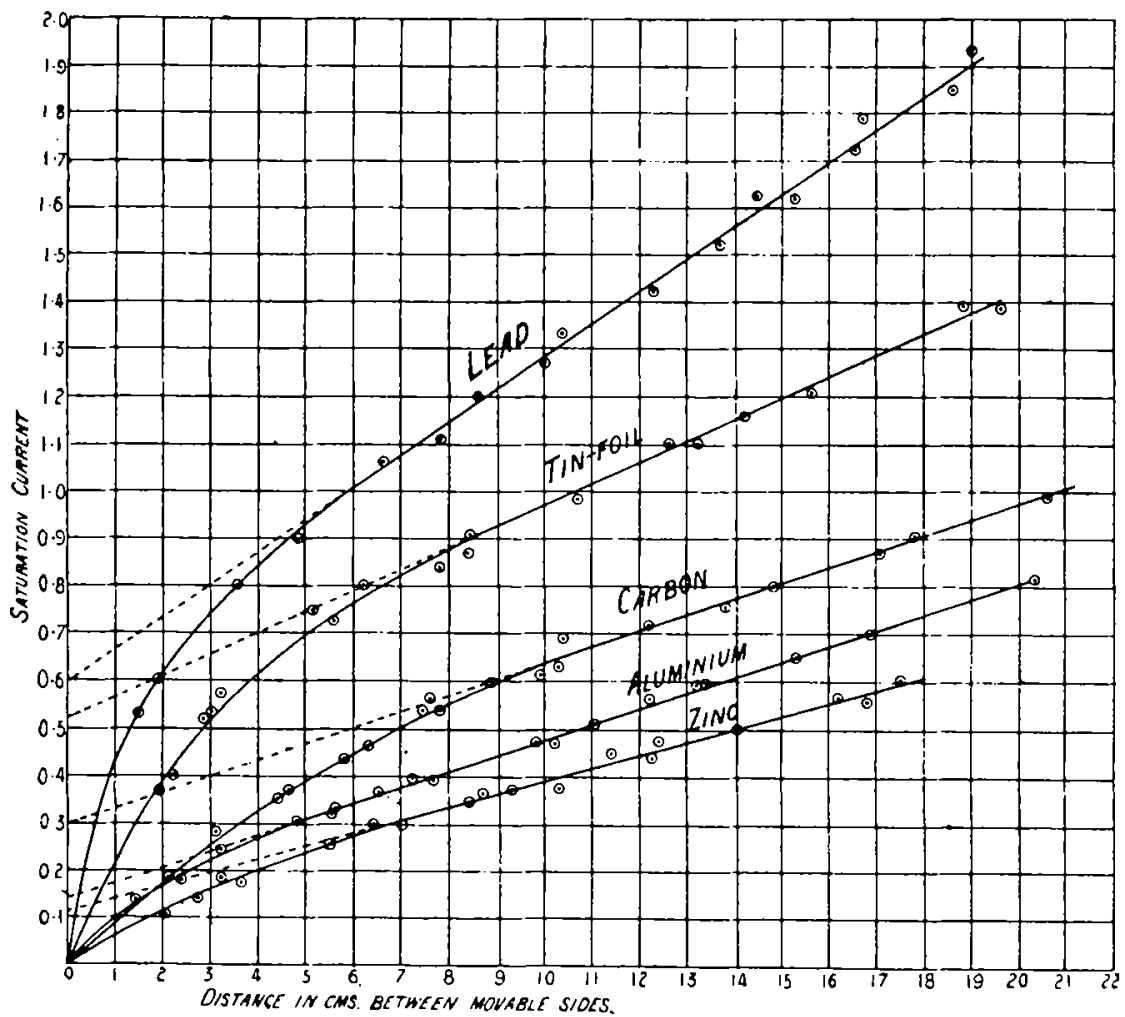

Fia. 2.

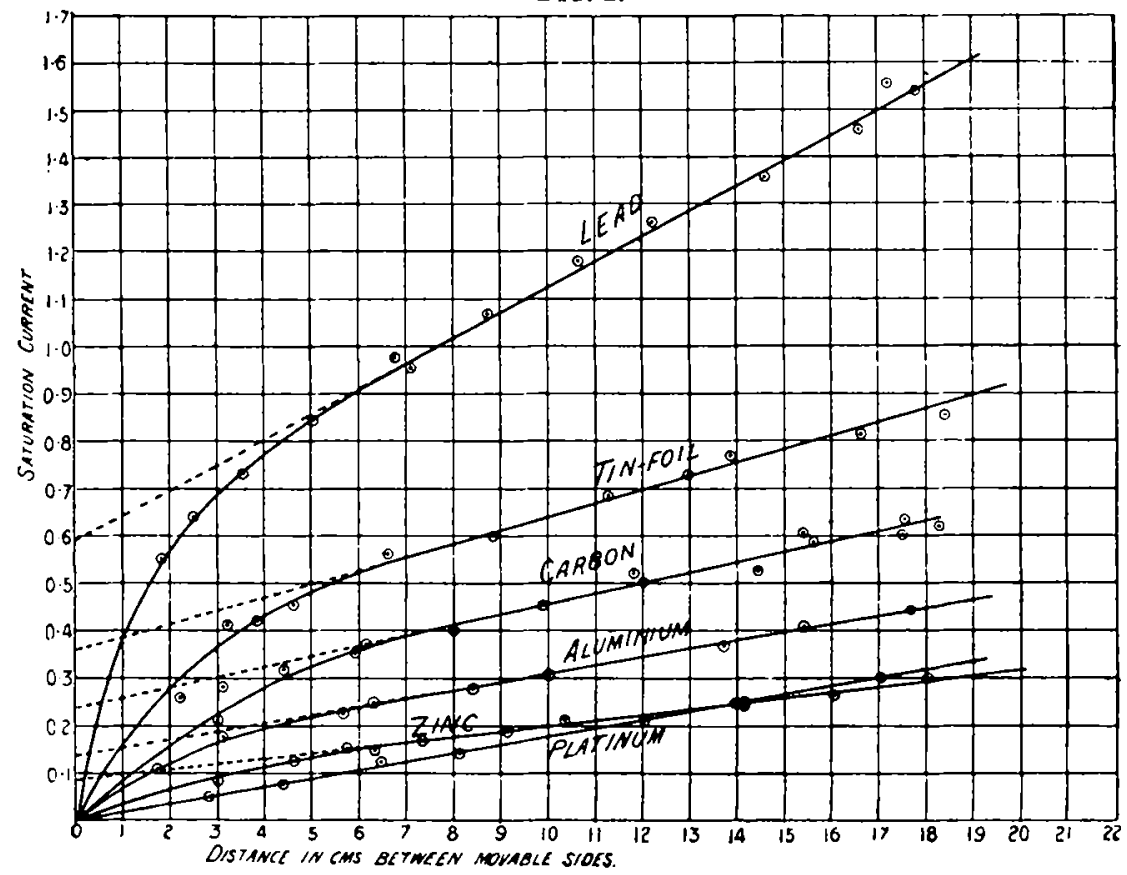

